\title{
Common Movement Disorders in Children: Diagnosis, Pathogenesis and Management
}

\author{
${\text { Isabelle Korn-Lubetzki }{ }^{*} \text {, Israel Steiner }}^{2}$ \\ ${ }^{1}$ Department of Neurology, Shaare Zedek Medical Center, Jerusalem, Israel; ${ }^{2}$ Department of Neurology, Rabin Medical Center, Beilinson \\ Campus, Petah Tiqva, Israel. \\ Email: *ikl@cc.huji.ac.il
}

Received December $14^{\text {th }}, 2011$; revised January $20^{\text {th }}, 2012$; accepted February $5^{\text {th }}, 2012$

\begin{abstract}
Movement disorders in childhood are a heterogeneous group of diseases with presentations that vary according to etiopathogenesis and age of onset. While sharing certain characteristics with the conditions that affect adults, they also have unique features that are determined by the metabolic, physiological and environmental distinctiveness of the developing brain. This context makes the nervous system of children vulnerable to various insults such as birth trauma, infections and toxicity. Some inborn errors of metabolism and genetic conditions selectively affect the young brain and psychological adaptation may also contribute to the occurrence and severity of certain conditions at this age group. The present review outlines the pathophysiology, clinical presentation and course, diagnosis and therapy of movement disorders in children. We also emphasize, when available, preventive and prophylactic measures and conclude by suggesting several avenues for future research in aspects that are currently not well understood.
\end{abstract}

Keywords: Movement Disorder; Children

\section{Introduction}

The objective of this review is to assist clinicians to be familiar with the clinical presentation, pathogenesis, epidemiology of movement disorders in childhood, to highlight our understanding of the cause and underlying mechanisms and to delineate avenues for future research in this area. The main thrust here is providing tools to reach clinical diagnosis, perform the proper etiological workup and describe available algorithms and treatment strategies.

\section{Definition, the Neuroanatomy and the Neurochemical Basis}

Most movement disorders can be attributed to dysfunction of the basal ganglia or to regions of the brain that are intimately interconnected with the basal ganglia. The basal ganglia represent a network of interconnected nuclei in the forebrain, diencephalon and midbrain $[1,2]$. These include the striatum (caudate, putamen, nucleus accumbens), the subthalamic nucleus, the globus pallidus (GP), and the substantia nigra. The striatum and subthalamic nucleus receive the majority of inputs from outside of the basal ganglia. Most of those inputs come from the cerebral cortex, but also form thalamic nuclei. The bulk of the outputs from the basal ganglia arise from the globus pallidus and the

${ }^{*}$ Corresponding author. substantia nigra pars reticulata. These outputs subsequently inhibit neurons in thalamic nuclei that in turn project to the frontal lobe, and to neurons in the pedunculopontine area.

Most of the movement disorders of basal ganglia origin are circuit disorders that result in impaired ability to facilitate desired movements, inhibit unwanted movements, or both $[1,3]$. Lesions or developmental abnormalities in one region can result in dysfunction of the entire circuit. Thus, similar clinical syndromes may arise from lesions at different points in the circuit. For example, dystonia may result from lesions in striatum (putamen or caudate), globus pallidus, or thalamus $[4,5]$. These may subsequently lead to dysfunction in the cerebral cortex and brainstem [6].

Basal ganglia circuitry is not limited to the motor domain, but also includes circuits involved in cognitive and affective function. Thus, many movement disorders of basal ganglia origin are accompanied by cognitive, affective, or behavioral dysfunction.

Most excitatory synapses of the basal ganglia and its connections use glutamate as neurotransmitter. Dopamine is the major neurotransmitter in the nigrostriatal dopamine system. Other important transmitters in these circuits include GABA, acetylcholine, norepinephrine and serotonin [7], and most pharmacologic treatments for movement disorders are targeted at these neurotransmitters. 


\section{Symptomatology (Table 1)}

Movement disorders can be hyperkinetic or hypokinetic. Hyperkinetic movement disorders are characterized by an excessive amount of unwanted or involuntary motor activity. These movements can be either rhythmic such as tremor, or irregular as are tics, chorea or hemiballismus. Stereotypies and myoclonus may be rhythmic or irregular.

Dyskinesia, synonymous to hyperkinetic movement disorders, includes tics, chorea, ballismus, dystonia, myoclonus, stereotypies, and tremor [8]. Tardive dyskinesia, a side effect of dopamine receptor antagonists, can appear even after the drug has been discontinued.

In hypokinetic movement disorders, intentional motor activity is abnormally reduced (bradykinesia) but strength is not significantly diminished while rigidity and postural instability are common. Parkinsonism, is the prototype and the most common hypokinetic movement disorder.

The diagnostic of movement disorder is almost always clinical. Description of the most important phenomena, eas- ily found in textbooks, will not be presented here [7-13].

\section{Epidemiology (Table 1)}

Most of the movement disorders in children are hyperkinetic. Hypokinetic basal ganglia syndromes are less common and are mainly present in juvenile forms of Parkinson's disease, Wilson's disease and Huntington's disease.

The most common etiology of movement disorders in children is probably cerebral palsy (CP), affecting 2.5 in 1000 live births in the United States [14]. Dystonia or choreo-athetosis are seen in dyskinetic cerebral palsy [15]. Dystonia starting in adolescence may be the presentation of Early-Onset Primary Dystonia (DYT1) [16].

$\mathrm{CP}$ is also the most common cause of chorea followed by medications side effects and Sydenham's chorea (SC). $\mathrm{SC}$ is now relatively infrequent in developed countries, attributed in part to aggressive antibiotics treatment against group A streptococci, but still prevalent in the third world [13,17-19].

Table 1. The clinical phenotype of movement disorders and their anatomical correlation.

Type of movement disorder Clinical description Prevalence in children Clinical aids for diagnosis Anatomical site

\section{Hypokinetic}

Bradykinesia

Slowed ability to start and continue movements
Very Rare

Rigidity, loss of postural reflexes
Contralateral substantia nigra. Mesencephalon

Hyperkinetic

\begin{tabular}{|c|c|c|c|c|}
\hline Chorea & $\begin{array}{l}\text { Involuntary, rapid, jerky } \\
\text { type arrhythmic movements }\end{array}$ & Not uncommon & $\begin{array}{l}\text { Uni or bilateral, hypotonia, } \\
\text { pendular reflexes }\end{array}$ & $\begin{array}{l}\text { Controlateral caudate nucleus, } \\
\text { putamen striatum }\end{array}$ \\
\hline Athetosis & $\begin{array}{l}\text { Slow, sinuous, } \\
\text { purposeless movements }\end{array}$ & Common & Intermittent hypotonia & $\begin{array}{l}\text { Striatum, } \\
\text { subthalamic } \\
\text { nucleus }\end{array}$ \\
\hline Dystonia & $\begin{array}{l}\text { Sustained movements with } \\
\text { abnormal posture }\end{array}$ & Common & $\begin{array}{l}\text { Generalized or focal, } \\
\text { increased tone }\end{array}$ & $\begin{array}{l}\text { Contralateral striatum, puta- } \\
\text { men, thalamus }\end{array}$ \\
\hline Myoclonus & $\begin{array}{l}\text { Sudden, rapid, twitchlike } \\
\text { muscle contractions }\end{array}$ & Mainly epileptic & Can be induced by stimuli & $\begin{array}{l}\text { Cerebral or cerebellar cortex } \\
\text { and dentate nuclei; } \\
\text { whole neuroaxis }\end{array}$ \\
\hline Tremor & $\begin{array}{l}8 \text { - to } 12-\mathrm{Hz} \text { tremor of the } \\
\text { outstretched hands, } \\
\text { or resting tremor }\end{array}$ & Common & $\begin{array}{l}\text { Essential: Enhanced by } \\
\text { anxiety physical activity } \\
\text { and sleep deprivation }\end{array}$ & $\begin{array}{l}\text { Brain stem } \\
\text { cerebellum spinal cord }\end{array}$ \\
\hline Ballismus & $\begin{array}{l}\text { Violent flinging movement } \\
\text { of an entire limb }\end{array}$ & Extremely Rare & $\begin{array}{l}\text { Usually unilateral, } \\
\text { exhausting }\end{array}$ & $\begin{array}{l}\text { Contralateral Subthalamic } \\
\text { nucleus, thalamus }\end{array}$ \\
\hline Tics & $\begin{array}{l}\text { Sudden, repetitive, } \\
\text { stereotyped motor } \\
\text { or phonic movements }\end{array}$ & common & $\begin{array}{l}\text { Stereotypical, diminish with } \\
\text { concentration, preceded by } \\
\text { urge, Comorbidities }\end{array}$ & Unknown \\
\hline Stereotypies & $\begin{array}{l}\text { Involuntary repetitive } \\
\text { rhythmic }\end{array}$ & Uncommon & Co morbidities & Unknown \\
\hline
\end{tabular}


Tics are very common in children. About $5 \%$ of schoolaged children have tics, with an estimated prevalence of $4 \%-19 \%$ [12]. The estimated prevalence of TS is 3.0 per 1000 , three times more in boys than in girls, and approximately twice as common in adolescence than in younger children [20-22]. Tics are usually associated with comor-bidities such as attention deficit hyperactive disorder (ADHD), learning disabilities, pervasive development disorder (PDD) or obsessive compulsive disorder (OCD) [12].

Prevalence of essential tremor in childhood is unknown [14]. Childhood onset is present in up to $15.5 \%$ of adult Asian patients with essential tremor [23]. In an epidemicological study in the city of Kolkata, India, there were 6/184 cases within the age group of $10-19$ years (prevalence of $0.70 / 1000)$ [24]. Age of onset is around $8-10$ years [25]. In a pediatric movement disorder clinic, $19 \%$ of patients had tremor as the sole or main feature [14], and up to $50 \%$ of individuals diagnosed with essential tremor may report an onset during childhood [26].

Myoclonus in children, mostly of epileptic origin, is beyond the scope of this review.

Drug induced movement disorders are prevalent (Table 2). Besides side effects to a prescribed drug, such as acute dystonia from metoclopramide [27], a movement disorder in a young child is not infrequently due to accidental ingestion of a drug taken by another household member.

It is important to remember that many movement disorders in young children are benign and transient. While present in PDD or Rett syndrome, stereotypies are also frequent in normal children [13].

\section{Causes for the Differences between Movement Disorders in Children and Adults}

Three factors set the nervous system of the pediatric age group apart from the mature adult brain: the biology of the young brain; environmental factors that are unique to this age group; genetic abnormalities that inherently present either early or late during life.

1) In the newborn brain, a less effective blood brain barrier (BBB), an impaired cerebrovascular autoregulation, and the high metabolic demands of the neonatal period are different than in the adults. Glutamate receptor density and activity are high in the perinatal period, creating a potential for a devastating effect when energy failure occurs. Overstimulation of these receptors can provoke excitotoxicity leading to death of neurons astrocytes or oligodendrocyte. Microglial activation by excitatory amino acids and leukocyte migration initiates an inflammatory response leading to an increase in regional cerebral blood flow and promoting astrocyte and oligodendrocyte injuries [28,29].

2) The non mature brain exposed to hypoxia-ischemia during birth can present later dyskinetic CP. Comparatively, adults who have sustained a severe hypoxia-ischemia, mainly after cardiac arrest, rarely suffer from movement disorders [30]. Another example is pharyngitis due to group A streptococcus that is very frequent in children and uncommon in adults.

3) Genetic background. Specific metabolic abnormalities such as glutaric aciduria type 1, Glucose transporter 1 (GLUT1) and Leigh disease occur exclusively in the young age. Most of the common genetic diseases involving the basal ganglia such as Wilson's disease, Huntington's disease or DYT1usually have an adult onset. Others may have a deleterious effect upon the developing brain, but none during adulthood. Thus, in Lesch Nyhan syndrome high level of uric acid causes at one year of age self mutilation, dystonia, choreoatheosis and ballismus but is not associated with any neurological signs in adults [31,32].

Table 2. Drug induced movement disorders.

\begin{tabular}{|c|c|c|}
\hline Type of movement disorder & Drug & Presence in sleep \\
\hline Bradykinesia & Typical neuroleptics and atypical antipsychotic & No \\
\hline Chorea/athetosis & $\begin{array}{l}\text { Phenytoin, carbamazepine, valproic acid, dopamine receptor blocking agents, } \\
\text { tricyclic antidepressants, theophylline, oral contraceptives, steroids, stimulants }\end{array}$ & No \\
\hline Dystonia & Typical neuroleptics, antipsychotics, metoclopramide & No \\
\hline Myoclonus & Epileptic myclonus can be aggravated by some antiepileptics & Yes \\
\hline Tremor & Tricyclic antidepressants, valproic acid, phenytoin, carmabazepine, theophylline & No \\
\hline
\end{tabular}


There are still many conditions that present in childhood and cannot be explained by these three factors or a combination of them. For example, onset of a primary tic disorder in adulthood is rare [10], while tics are very frequent in childhood. Some of the movement disorders are specifically childhood age dependent and transient such as jitteriness, simple tics, spasmus nutans, transient idiopathic dystonia, or benign myoclonus of infancy [33].

\section{Pathogenesis and Description of Common Conditions}

Basal ganglia of the developing brain are susceptible to several insults, the most prevalent being hypoxia-ischemia, hyperbilirubinemia and infection-associated.

\subsection{Hypoxia-Ischemia}

Abnormalities within the basal ganglia are observed in up to $84 \%$ of patients with perinatal hypoxia-ischemia culminating in shrinkage of the striatum [34]. In the acute phases necrotic or apoptotic neurons can be identified. Later larger zones of necrosis can lead to severe neuronal loss and glial scars. Defects in myelination can result in a marbled gross appearance (hypermyelination-status marmotratus) or in dysmyelination [35].

Vulnerability to hypoxia-ischemia is mainly a feature of the border zones between the major cerebral arteries ("watershed"). In the striatum, neuronal death is probably related to the density of the excitatory glutamate receptors. Striatal GABA-ergic neurons are also sensitive to asphyxia while astrocytes and oligodendrocytes, expressing glutamate receptors as well, participate in basal ganglia injury [34]. Neurons die by glutamate-mediated excitotoxicity involving downstream caspase-dependent and caspase-independent cell death pathways [36]. Delayed apoptosis can extend over days to weeks.

MR-spectroscopy analysis with measures of N-acetylaspartate (NAA) and choline concentrations can identify basal ganglia damage in severely asphyxiated neonates and can help to predict unfavorable outcome [37].

\subsection{Hyperbilirubinemia}

The basal ganglia of the newborn are very susceptible to increased blood levels of bilirubin. Lesions of the GP, substantia nigra, subthalamic nuclei, as well as cochlear, and oculomotor nuclei, hippocampus, and cerebellum have been demonstrated in kernicterus. Marked loss of neurons, demyelination, and prominent gliosis are present $[38,39]$.

\subsection{Infections}

The influence of environmental factors unique to the pediatric age group is illustrated by the basal ganglia dysfunction following streptococcal infections. The basal ganglia are the major target of immune-mediated post strep-tococcal infection CNS damage causing SC. Group-A $\beta$-haemolytic streptococcal (GABHS) infections (usually pharyngitis) provoke synthesis of antibodies that cross-react between the rheumatogenic strains of streptococci and human basal ganglia epitopes. Such antibodies are present in 50\% $90 \%$ of patients with SC $[17,40]$. The possibility that PANDAS (pediatric autoimmune neuropsychiatric disorders associated with streptococcal infections) is also a post streptococcal disorder in some patients has been raised by some [41]. This is also relevant for encephalitis lethargica, where autoantibodies reactive against basal ganglia antigens are present in $95 \%$ of patients, suggesting a post infectious dysimmune mechanism [42].

Infective pathogens such as herpes simplex and measles viruses can rarely involve the basal ganglia as part of acute or chronic encephalitis [43].

\subsection{Cerebral Palsy (CP)}

$\mathrm{CP}$ is a group of disorders attributed to non-progressive disturbances that occurred in the developing fetal or infant brain [44]. CP is generally categorized into spastic, extrapyramidal/dyskinetic, and mixed $[15,45]$. Dyskinetic CP is more likely to originate closer to pregnancy term or in early infancy. Perinatal asphyxia in term infants accounts for less than $15 \%$ of $\mathrm{CP}$ in developed countries with a higher incidence in underdeveloped areas [46]. The severity of the MRI and histopathological pathology in the thalamus and basal ganglia correlates with the clinical outcome. A mild abnormal pattern gives a purely dyskinetic $\mathrm{CP}$, while the moderate form results in dyskinetic spastic $\mathrm{CP}$ and severe types are associated with spastic CP. On MRI, hyperintense signal and atrophy in the putamen and thalamus is characteristic of asphyxia, while the presence of abnormal signal in the globus pallidus is strongly associated with genetic-metabolic diseases [45]. Diagnosis is dependent on the medical history with evidence for neonatal hypoxia-ischemia [44]. While the majority of children with CP present with symptoms as infants or toddlers, symptom onset may be delayed up to 2 years in dystonic CPs [47]. The clinical picture of dyskinetic CP evolves gradually from diffuse hypotonia with active reflexes in infancy to choreoathetois/dystonia during childhood [34].

\subsection{Kernicterus}

Kernicterus remains a significant problem, due in part to earlier hospital discharge of neonates and relaxation of rigorous treatment criteria for hyperbilirubinemia [38]. Severe damage can occur with relatively low total serum bilirubin levels in preterms infants [48]. By 2 weeks of age, the infant usually has developed hypertonia, opisthotonus, extensor spasms, and sometimes seizures. By 4 years of age athetosis, dystonia, rigidity, tremor, hearing loss, loss 
of dental enemal and mental retardation are evident.

\subsection{Drugs (Table 2)}

Movement disorders in children can be caused by a variety of medications. Of particular importance are the side effects associated with antiepileptic drugs that can cause tremor, tics and chorea $[17,49]$. Stimulants can produce tics and less commonly chorea [49]. Theophylline can induce tremor and to a lesser degree chorea $[17,49]$.

Dopamine receptor blockers such as typical neuroleptics or atypical antipsychotics can give all types of movement disorders [49]. Hypokinetic syndrome with Parkinsonism, frequent with typical neuroleptics is also present with atypical antipsychotics such as risperidone. Dystonia is seen more with typical neuroleptics, still in use for their low cost [50].

Four studies involving 611 children (mean age 10.2 years) with autism or disruptive behavior disorders, showed that annual tardive dyskinesia rates were $0.35 \%$ with second generation antipsychotics [51]. In 783 children receiving risperidone, quetiapine, or olanzapine for a mean of 329.6 days, the annualized tardive dyskinesia rate for risperidone was $0.30 \%$. Tardive dyskinesia resolved within weeks after antipsychotic discontinuation [52].

\subsection{SC}

This is one of the major criteria of rheumatic fever (RF). Onset is usually around the age of $8-9$ years, with a female preponderance [17]. It can be bilateral but $20 \%$ of patients have hemichorea. Behavioral abnormalities are common and might mask the movement disorder which can be discrete. Diagnosis is based on the clinical context and requires exclusion of other conditions. SC is usually a self limited disorder but recurrences, probably not all related to $\mathrm{RF}$, are described in up to $40 \%$ of the patients $[19,53]$.

\subsection{PANDAS}

Children with PANDAS show dramatic onset of motor or vocal tics, obsessions, and abnormal motor activity with temporal relation to a GABHS infection. [41] The entity of PANDAS remains controversial and it is not clear that it represents a unique subset of the larger spectrum of prepubertal patients with these neuropsychiatric features [54-56].

\subsection{Inherited Abnormalities (Table 3)}

These are rare causes of movement disorders in children and are beyond the scope of the present review. Most are

Table 3. Some inherited conditions causing movement disorders in childhood that should be considered in the differential diagnosis.

\begin{tabular}{|c|c|c|c|c|}
\hline Etiology & Age at onset & Clinical signs & EEG \& Imaging & $\begin{array}{c}\text { Laboratory findings other } \\
\text { than genetic testing }\end{array}$ \\
\hline $\begin{array}{l}\text { Glutaric aciduria } \\
\text { type } 1\end{array}$ & 5 to 10 months & $\begin{array}{l}\text { Acute encephalopathy followed } \\
\text { by dystonia, motor impairment, } \\
\text { macrocephaly }\end{array}$ & $\begin{array}{c}\text { CT/MRI: Fronto temporal } \\
\text { atrophy }\end{array}$ & $\begin{array}{c}\text { Organic acids in urine, } \\
\text { enzyme assay }\end{array}$ \\
\hline $\begin{array}{l}\text { Glucose transporter } \\
1 \text { deficiency syndrome }\end{array}$ & Infancy & $\begin{array}{l}\text { Seizures, developmental delay, } \\
\text { complex movement disorder }\end{array}$ & EEG improves post prandially & $\begin{array}{c}\text { Low glucose } \\
\text { concentration in CSF }\end{array}$ \\
\hline $\begin{array}{l}\text { Lesch Nyhan } \\
\text { syndrome }\end{array}$ & $3-18$ months & $\begin{array}{c}\text { Self mutilation, facial grimacing, } \\
\text { involuntary writhing, repetitive } \\
\text { movements of the arms }\end{array}$ & Development of kidney stones & Hyperuricemia \\
\hline Leigh's disease & Birth-1st year & $\begin{array}{l}\text { Diffuse encephalopathy, } \\
\text { dysphagia, dystonia myoclonus, } \\
\text { hypotonia central respiratory } \\
\text { insufficiency }\end{array}$ & $\begin{array}{l}\text { MRI: Periventricular leukomala- } \\
\text { cia, hyperintense T2 signal in the } \\
\text { basal ganglia and thalami. }\end{array}$ & High serum/CSF lactate \\
\hline $\begin{array}{l}\text { Pantothenate } \\
\text { kinase-associated } \\
\text { neurodegeneration }\end{array}$ & 1st decade & $\begin{array}{c}\text { Delayed motor and language, } \\
\text { later choreoathetosis, dystonia, } \\
\text { dysarthria, } \\
\text { dysphasia, spasticity, retinopathy }\end{array}$ & MRI: Eye of the tiger sign & Non contributing \\
\hline Wilson's disease & $1^{\text {st }}-2^{\text {nd }}$ decade & $\begin{array}{l}\text { Dysarthria, gait disturbances, } \\
\text { risus sardonicus, dystonia, } \\
\text { rigidity, tremor, dysphagia }\end{array}$ & $\begin{array}{l}\text { MRI: High signal in basal } \\
\text { ganglia, dentate nuclei \& } \\
\text { cerebellum on T2 }\end{array}$ & $\begin{array}{l}\text { Kaiser Fleischer ring, } \\
\text { low serum ceruloplasmine }\end{array}$ \\
\hline $\begin{array}{l}\text { Hungtington's } \\
\text { disease }\end{array}$ & $2^{\text {nd }}$ decade & $\begin{array}{c}\text { Neurological and psychiatric } \\
\text { symptoms, chorea, rigidity, } \\
\text { hypokinesia }\end{array}$ & $\begin{array}{l}\text { MRI: Non specific generalized } \\
\text { or striatal atrophy }\end{array}$ & Non contributing \\
\hline $\begin{array}{l}\text { Early onset torsion } \\
\text { dystonia (DYT1) }\end{array}$ & $\begin{array}{l}\text { Between } 3 \\
\text { and } 26 \text { years }\end{array}$ & $\begin{array}{c}\text { Ashkenazi jewish, } \\
\text { dystonia affecting first one arm } \\
\text { or leg progressing to generalized } \\
\text { or multifocal }\end{array}$ & Non contributing & Non contributing \\
\hline
\end{tabular}


due to already recognized metabolic defects. They are summarized in Table 3 where the typical signs and abnormal laboratory findings are presented in order to rule out these diseases in the differential diagnosis of the more common movement disorders [32,50,57-59].

\subsection{Miscellaneous: Tremor, Tics, Wilson's Disease, Paroxysmal Conditions}

Tremor in childhood is seen in a variety of etiologies, mainly metabolic (Table 4) and with drug toxicity (Table 2).

In the immediate postpartum period, excessive tremulous behavior, referred to as jitteriness, involves the entire body. Up to $44 \%$ of healthy newborns will exhibit some jitteriness, a benign condition resolving within a few months [26].

The main tremor of childhood is essential tremor. It is characterized by a $4-11 \mathrm{~Hz}$ frequency that most commonly involves the arms or head, sometimes responsive to ethanol. The neurological examination has to be normal to exclude other processes [26].

Tics (including TS). Most children present with a transient motor tic lasting from 4 weeks to 1 year involving a single muscle in the head, face, neck or arms Tics are more common in boys [12]. Transient tics may also, infrequently, be phonic. Tics may be complex motor (touching, smelling, shaking, jumping) or complex phonic (humming, echolalia, whistling, singing). Coprolalia (uttering obscenities) is reported in $10 \%$ of TS patients. If both motor and phonic tics have persisted for more than a year, a diagnosis of TS is appropriate. In TS boys are affected up to 5 times more and have an earlier onset of tics than girls [12].

Wilson's disease. Although rare, represents the classical treatable movement disorder. Nearly half of all patients present at adolescence or early adulthood with Parkinsonism, tremor, ataxia, titubation, chorea, seizures, dysarthria, and dystonia [58].

Paroxysmal movement disorders are a relatively uncommon but important subset of movement disorders. They include paroxysmal dyskinesias, stereotypies, benign paroxysmal torticollis, spasmus nutans [60]. Sandifer syndrome consists of attacks of gastro-oesophageal reflux with spastic torticollis and dystonic body movements. It is hypothesized that the positioning of the head provides relief from abdominal discomfort caused by acid reflux [61]. Between the attacks the neurological examination is completely normal.

The main and more common possible causes of the various movement disorders are detailed in Table 4.

\section{Diagnosis (Tables 1-4)}

A meticulous approach is necessary when obtaining the
Table 4. Etiology of the various movement disorders.

\begin{tabular}{|c|c|}
\hline Type of movement & Etiology \\
\hline \multirow[t]{3}{*}{ Bradykinesia } & Juvenile Parkinson's disease \\
\hline & Juvenile Wilson's disease \\
\hline & Drugs \\
\hline \multirow[t]{9}{*}{ Chorea } & Inherited \\
\hline & Sydenham's \\
\hline & SLE \\
\hline & Thyrotoxicosis \\
\hline & Hypoparathyroidism \\
\hline & Disorder of sodium/glucose \\
\hline & Renal failure \\
\hline & Basal ganglia infarction/hemorrhage \\
\hline & Drugs \\
\hline \multirow[t]{3}{*}{ Athetosis } & Perinatal hypoxia /trauma \\
\hline & Kernicterus \\
\hline & Sandifer syndrome \\
\hline \multirow[t]{9}{*}{ Dystonia } & Perinatal hypoxia /trauma \\
\hline & DYT1 \\
\hline & Encephalitis \\
\hline & Basal ganglia stroke/tumor \\
\hline & Juvenile Wilson’s disease \\
\hline & Mitochondrial encephalopathy \\
\hline & DOPA responsive \\
\hline & Sandifer syndrome \\
\hline & Drugs \\
\hline \multirow[t]{11}{*}{ Myoclonus } & Epileptic \\
\hline & Mitochondrial (MERRF) \\
\hline & GM2 gangliosidosis \\
\hline & Biotinidase/Carboxylase deficiency \\
\hline & Renal/hepatic failure \\
\hline & Hyperglycemia \\
\hline & SSPE \\
\hline & Opsoclonus myoclonus syndrome \\
\hline & Post hypoxia \\
\hline & Spinal cord tumor \\
\hline & Drugs \\
\hline \multirow[t]{7}{*}{ Tremor } & Essential \\
\hline & Hypoglycemia \\
\hline & Hypocalcemia \\
\hline & Hypomagnesemia \\
\hline & Perinatal hypoxia \\
\hline & Hyperthyroidism \\
\hline & Drugs \\
\hline \multirow[t]{3}{*}{ Tics } & PANDAS \\
\hline & TS \\
\hline & Drugs \\
\hline \multirow[t]{4}{*}{ Stereotypies } & Mental retardation \\
\hline & PDD \\
\hline & Rett syndrome \\
\hline & Healthy children \\
\hline
\end{tabular}

DYT1-Early-onset primary dystonia; MERRF-Myoclonic epilepsy with ragged red fibers; PANDAS-pediatric autoimmune neuropsychiatric disorders associated with streptococcal infections; PDD-Pervasive developmental disorder; SLEsystemic lupus erythematosus; SSPE-subacute sclerosing panencephalitis; TSTourette syndrome. 
history: birth and neonatal antecedents such as hypoxiaischemia or kernicterus, positive family history, age at onset, drug history, precipitating factors should be obtained. The most important aspect however is the definition of the clinical phenomenon, with an extended period of observation, using if necessary videotapes. Based on the type of movement disorder and the clinical setup and context, the workup is tailored for each individual patient. Eventually the diagnosis will also rely on clinical hints: e.g.: 1) in movement disorders there is no aura nor post ictal state, but some antiepileptic drugs can improve both epilepsy and movement disorders and the therapeutic response should not be taken as a diagnostic criteria [14]; 2) relation to sleep can help to differentiate the type of movement abnormality (Table 2); 3) tics can be voluntarily suppressed, sometimes for extended periods of time. [11] 4) certain abnormalities may occur in attacks. A meticulous neurological examination is essential in order to classify the various etiologies. While in tics or in benign metabolic conditions (e.g. hyponatremia) there will not be any abnormal sign except for the movement disorder, spasticity can be found in $\mathrm{CP}$, and encephalopathy in dis- eases such as GLUT1 and glutaric aciduria.

Routine blood tests including biochemistry, thyroid functions, and ceruloplasmin are nearly always needed [9]. When a genetic or ongoing metabolic disease is suspected, specific blood and urine testing, EEG and structural/ functional brain imaging should be performed according to the clinical context. Genetic workup is necessary in suspected cases.

\section{Therapy (Table 5)}

The literature that summarizes or reviews therapeutic options for movement disorders in children is limited. This is due in part to the lack of controlled therapeutic trials and evidence based data. The therapeutic approach is based on the etiology of the disorder and the phenomenology, and in many instances on both $[31,62,63]$.

\subsection{Therapy Based Solely or Mainly on the Etiology}

In case of drug toxicity reducing the dosage or avoiding the incriminated compound is the obvious therapeutic approach.

Table 5. Treatment options and doses in each movement disorder.

\begin{tabular}{|c|c|c|}
\hline Type of movement disorder & Treatment options & Dose: Initial-maximal \\
\hline \multirow[t]{4}{*}{ Bradykinesia } & Wilson: penicillamine & \\
\hline & L DOPA & $1-10 \mathrm{mg} / \mathrm{kg} /$ day \\
\hline & Dopamine agonists & Depends on medication \\
\hline & Anticholinergics & Depends on medication \\
\hline \multirow[t]{4}{*}{ Chorea } & Valproic acid & $20-40 \mathrm{mg} / \mathrm{kg}$ \\
\hline & Carbamazepine & $10-20 \mathrm{mg} / \mathrm{kg}$ \\
\hline & Pimozide & $0.5-10 \mathrm{mg} / \mathrm{d}$ \\
\hline & Prophyllactic penicillin in SC & $1,200,000$ units/month \\
\hline Athetosis & Trihexyphenidil & $0.2-2.5 \mathrm{mg} / \mathrm{kg} / \mathrm{d}$ \\
\hline \multirow[t]{3}{*}{ Dystonia } & DBS & \\
\hline & L DOPA & $25-300 \mathrm{mg} /$ day \\
\hline & Trihexyphenidil & $0.2-2.5 \mathrm{mg} / \mathrm{kg} / \mathrm{d}$ \\
\hline \multirow[t]{3}{*}{ Tremor } & Propranolol & $20-80 \mathrm{mg} / \mathrm{d}$ \\
\hline & Primidone & $12.5-200 \mathrm{mg} /$ day \\
\hline & Topiramate & $50 \mathrm{mg} /$ day \\
\hline \multirow[t]{5}{*}{ Tics } & Metoclopramide & $5-40 \mathrm{mg} / \mathrm{d}$ \\
\hline & Risperidone & $0.01-0.06 \mathrm{mg} / \mathrm{kg} / \mathrm{d}$ \\
\hline & Clonidine & $0.05-0.5 \mathrm{mg} / \mathrm{d}$ \\
\hline & Guanfacine & $0.5-4 \mathrm{mg} / \mathrm{d}$ \\
\hline & Olanzapine & $1.25-14.5 \mathrm{mg} / \mathrm{d}$ \\
\hline
\end{tabular}

DBS-Deep brain stimulation; SC-Sydenham's chorea. 
It is recommended to treat patients with Sydenham's chorea with penicillin prophylaxis up to the age of 21 years to prevent recurrent attacks, even if they do not have other signs of RF [64]. There are no controlled studies regarding the specific treatment of the chorea. Valproic acid has become the first drug of choice. Carbamazepine can also be effective. Dopamine-receptor blocking drugs are indicated only if other medications fail $[17,53,62]$.

No specific treatment has been proved to be effective in the treatment of PANDAS [41].

The traditional treatment of Wilson's disease addresses the acute chelation of copper with $\delta$-penicillamine, but more recent less toxic strategies are trientine and zinc or ammonium tetrathiomolybdate [7].

\subsection{Therapy Aimed at the Neurological Phenomenology}

Dystonia. Dopa-responsive dystonia, an autosomal dominant disorder with worsening of symptoms in the evening dramatically responds to low dose Levodopa. Trihexyphenidyl was not shown to be superior to placebo in a randomized, double-blinded, placebo-controlled, crossover trial conducted with 16 participants with dystonic cerebral palsy. Side effects were common [65].

Essential tremor. Younger children typically have minimal impairment, and the main issue at that age is to reassure the parents. Caffeine consumption should be reduced. Only $61 \%$ of 39 children evaluated by Jankovic were medically treated with primidone or propranolol [21].

Tics. Education and reassurance of the parents remains the effective approach. Treatment of tics is needed only when they cause functional impairment. Clonidine and guanfacine are considered as first line medications [66]. Metoclopramide was significantly more effective than placebo in reducing tics in 27 children with TS or a chronic tic disorder [67]. Olanzapine produced statistically significant reductions of aggression and tic severity in ten subjects with a primary diagnosis of TS and a history of aggressive behavior [68]. Both risperidone and clonidine were effective and reduced tics in $5 / 21(25 \%)$ treated subjects aged 7 to 17 years [69].

One important issue is the treatment of tics appearing or worsening concomitantly with ADHD. Prior recommendations were to avoid methylphenidate in these children. However in a multicenter, randomized, double-blind clinical trial, 136 children with ADHD and a chronic tic disorder were randomly administered clonidine alone, methyphenidate alone, combined treatment, or placebo for 16 weeks. Compared to placebo, therapy was effective: tic severity improved in all treatment groups, mainly with combined treatment. Clonidine was more helpful than methyphenidate but was associated with sedation [70].

\subsection{Surgical and Psychological Treatment}

Deep brain stimulation (DBS) has been shown to be effective in the treatment of dystonia in adults [71]. Scattered reports of improvement of dystonia with DBS have been documented in children, while patients with dystonia due to perinatal asphyxia might benefit less, due in part to already existing contractures [72].

Severe cases of TS responded to DBS [73,74]. Even neuropsychological and psychiatric co-morbidities may improve after DBS [75].

Botulinum toxin injections can be effective in dystonia, spasticity ans some particularly disabling motor tics [11].

Behavioral therapy has been efficacious in motor stereotypies [13], but not particularly helpful for patients with disabling tics [11].

\section{The Future}

While the phenomenological arena of movement disorders in the pediatric age group has been mapped quite satisfactory, the field still lacks information and evidence-based data in two aspects. The etiology and pathogenesis of several acquired conditions such as PANDAS and TS is still obscure and should be pursued. More important, double blind controlled clinical studies to evaluate and delineate the best therapeutic approach to most of the conditions described is still missing: what is the best therapy for TS? How should tremor be approached and what is the optimal therapy of tardive dyskinesia in children are examples of questions that should be addressed.

The issue of prevention is, likewise, of importance. Control and prevention of neonatal asphyxia and reducing the permanent damage is a worthy objective for the obstetrician and for this goal the developing of neuroprotective compounds and modalities is of paramount importance. Last, guidelines to avoid the use of agents that may produce movement disorders as transient and permanent side effect should be issued.

\section{REFERENCES}

[1] J. W. Mink, "The Basal Ganglia: Focused Selection and Inhibition of Competing Motor Programs," Progress in Neurobiology, Vol. 50, No. 4, 1996, pp. 381-425. doi:10.1016/S0301-0082(96)00042-1

[2] J. P. Bolam, J. J. Hanley, P. A. Booth and M. D. Bevan, "Synaptic Organisation of the Basal Ganglia," Journal of Anatomy, Vol. 196, No. 4, 2000, pp. 527-542. doi:10.1046/j.1469-7580.2000.19640527.x

[3] J. W. Mink, "The Basal Ganglia and Involuntary movements: Impaired Inhibition of Competing Motor Patterns," Archives of Neurology, Vol. 60, No. 10, 2003, pp. 13651368. doi:10.1001/archneur.60.10.1365

[4] C. D. Marsden, J. A. Obeso, J. J. Zarranz and A. E. Lang "The Anatomical Basis of Symptomatic Hemidystonia." 
Brain; Vol. 108, No. Pt. 2, 1985, pp. 463-483. doi:10.1093/brain/108.2.463

[5] K. P. Bhatia and C. D. Marsden, "The Behavioural and Motor Consequences of Focal Lesions of the Basal Ganglia in Man," Brain, Vol. 117, No. 4, 1994, pp. 859-876. doi:10.1093/brain/117.4.859

[6] M. Hallett, "Overview of Human Tremor Physiology," Movement Disorders, Vol. 13, Suppl. 3, 1998, pp. 43-48. doi:10.1002/mds. 870131308

[7] J. Jankovic and K. M. Shannon, "Movement Disorders," In: W. G. Bradley, R. B. Daroff, G. M. Fenichel and J. Jankovic, Eds., Neurology in Clinical Practice, 5th Edition, Butterworth Heinemann Elsevier, Philadelphia, 2008, p. 2081.

[8] B. L. Schlaggar and J. W. Mink, "Movement Disorders in Children," Pediatric Review, Vol. 24, No. 2, 2003, pp. 39-51. doi:10.1542/pir.24-2-39

[9] R. P. Simon, D. A. Greenberg and M. J. Aminoff, "Movement Disorders," In: R. P. Simon, D. A. Greenberg and M. J. Aminoff, Eds., Clinical Neurology, 7 Edition, McGraw Hill, New York, 2009.

[10] J. F. Leckman, "Phenomenology of Tics and Natural History of Tic Disorders," Brain Development, Vol. 25, Suppl. 1, 2003, pp. S24-28. doi:10.1016/S0387-7604(03)90004-0

[11] D. Shprecher and R. Kurlan, "The Management of Tics," Movement Disorders, Vol. 24, No. 1, 2009, pp. 15-24. doi: $10.1002 / \mathrm{mds} .22378$

[12] J. M. Dooley, "Tic Disorders in Childhood," Seminars in Pediatric Neurology, Vol. 13, No. 4, 2006, pp. 231-242. doi:10.1016/j.spen.2006.09.004

[13] D. S. Wolf and H. S. Singer, "Pediatric Movement Disorders: An Update," Current Opinion in Neurology, Vol. 21, No. 4, 2008, pp. 491-496. doi:10.1097/WCO.0b013e328307bf1c

[14] M. R. Delgado and A. L. Albright, "Movement Disorders in Children: Definitions, Classifications, and Grading Systems," Journal of Child Neurology, Vol. 18, Suppl. 1, 2003, pp. S1-8.

[15] T. M. O'Shea, "Diagnosis, Treatment, and Prevention of Cerebral Palsy," Clinical Obstetrics and Gynecology, Vol. 51, No. 4, 2008, pp. 816-828. doi:10.1097/GRF.0b013e3181870ba7

[16] G. Zorzi, F. Zibordi, B. Garavaglia and N. Nardocci, "Early Onset Primary Dystonia," European Journal of Paediatric Neurology, Vol. 13, No. 6, 2009, pp. 488-492. doi:10.1016/j.ejpn.2008.12.001

[17] F. Cardoso, K. Seppi, K. J. Mair, G. K. Wenning and W. Poewe, "Seminar on Choreas," Lancet Neurology, Vol. 5, No. 7, 2006, pp. 589-602. doi:10.1016/S1474-4422(06)70494-X

[18] I. Korn-Lubetzki and A. Brand, "Sydenham's Chorea in Jerusalem: Still Present," Israel Medical Association Journal, Vol. 6, No. 8, 2004, pp. 460-452.

[19] I. Korn-Lubetzki, A. Brand and I. Steiner, "Recurrence of Sydenham's Chorea: Implications for Pathogenesis," Archives of Neurology, Vol. 61, No. 8, 2004, pp. 1261-1264. doi:10.1001/archneur.61.8.1261
[20] Centers for Disease Control and Prevention (CDC), "Prevalence of diagnosed Tourette Syndrome in Persons Aged 6-17 Years United States, 2007," Morbidity and Mortality Wkeekly Report, Vol. 58, No. 21, 2008, pp. 581-585.

[21] J. F. Leckman, M. H. Bloch, L. Scahill and R. A. King, "Tourette Syndrome: The Self Under Siege," Journal of Child Neurology, Vol. 21, No. 8, 2006, pp. 642-649. doi:10.1177/08830738060210081001

[22] R. Jin, R. Y. Zheng, W. W. Huang, H. Q. Xu, B. Shao, H. Chen and L. Feng, "Epidemiological Survey of Tourette Syndrome in Children and Adolescents in Wenzhou of P. R. China," European Journal of Epidemiology, Vol. 20, No. 11, 2005, pp. 925-627. doi:10.1007/s10654-005-2953-Z

[23] E. K. Tan, S. Y. Lum and K. M. Prakash, "Clinical Features of Childhood Onset Essential Tremor," European Journal of Neurology, Vol. 13, No. 12, 2006, pp. 1302 1305. doi:10.1111/j.1468-1331.2006.01471.x

[24] S. K. Das, T. K. Banerjee, T. Roy, D. K. Raut, A. Chaudhuri and A. Hazra, "Prevalence of Essential Tremor in the City of Kolkata, India: A House-to-House Survey," European Journal of Neurology, Vol. 16, No. 7, 2009, pp. 801-807. doi:10.1111/j.1468-1331.2009.02589.x

[25] J. Jankovic, J. Madisetty and K. D. Vuong, "Essential Tremor among Children," Pediatrics, Vol. 114, No. 5, 2004, pp. 1203-1205. doi:10.1542/peds.2004-0031

[26] S. Keller and L. S. Dure "Tremor in Childhood," Seminar in Pediatric Neurology, Vol. 16, No. 2, 2009, pp. 60-70. doi:10.1016/j.spen.2009.03.007

[27] A. M. Hibbs and S. A. Lorch, "Metoclopramide for the Treatment of Gastroesophageal Reflux Disease in Infants: A Systematic Review," Pediatrics, Vol. 118, No. 2, 2006, pp. 746-752. doi:10.1542/peds.2005-2664

[28] A. Alvarez-Díaz, E. Hilario, F. G. de Cerio, A. Valls-i -Soler and F. J. Alvarez-Díaz, “ Hypoxic-Ischemic Injury in the Immature Brain: Key Vascular and Cellular Players," Neonatology, Vol. 92, No. 4, 2007, pp. 227-235. doi:10.1159/000103741

[29] C. McLean and D. Ferriero, "Mechanisms of HypoxicIschemic Injury in the Term Infant," Seminar in Perinatology, Vol. 28, No. 6, 2004, pp. 425-432. doi:10.1053/j.semperi.2004.10.005

[30] S. Khot and D. L. Tirschwell, "Long-Term Neurological Complications after Hypoxic-Ischemic Encephalopathy," Seminar in Neurology, Vol. 26, No. 4, 2006, pp. 422-431. doi:10.1055/s-2006-948323

[31] J. Menkes, "Heredodegenerative Diseases," In: J. H. Menkes, H. B. Sarnat and B. L. Maria, Eds., Child Neurolog, 7th Edition, Lippincott Williams \& Wilkins, Philadelphia, 2005, p. 163.

[32] J. H. Menkes and W. R. Wilcox, "Inherited Metabolic Diseases of the Nervous System," In: J. H. Menkes, H. B. Sarnat and B. L. Maria, Eds., Child Neurology, 7th Edition, Lippincott Williams \& Wilkins, Philadelphia, 2005, p. 29.

[33] E. Fernandez-Alvarez and J. Aicardi, (Eds.), "Movement Disorders in Children," MacKeith Press, London, 2001, p. 19. 
[34] J. H. Menkes and H. B. Sarnat, "Perinatal Asphyxia and Trauma," J. H. Menkes, H. B. Sarnat and B. L. Maria, Eds., Child Neurology, 7th Edition, Lippincott Williams \& Wilkins, Philadelphia, 2005, p. 367.

[35] R. D. Folkerth, "Neuropathologic Substrate of Cerebral palsy," Journal of Child Neurology, Vol. 20, No. 12, 2005, pp. 940-949. doi:10.1177/08830738050200120301

[36] M. V. Johnston and A. H. Hoon Jr., "Possible Mechanisms in Infants for Selective Basal Ganglia Damage from Asphyxia, Kernicterus, or Mitochondrial Encephalopathies," Journal of Child Neurology, Vol. 15, No. 9, 2000, pp. 588-591. doi:10.1177/088307380001500904

[37] C. Boichot, P. M. Walker, C. Durand, M. Grimaldi, S. Chapuis, J. B. Gouyon and F. Brunotte, "Term Neonate Prognoses after Perinatal Asphyxia: Contributions of MR Imaging, MR Spectroscopy, Relaxation Times, and Apparent Diffusion Coefficients," Radiology, Vol. 239, No. 3, 2006, pp. 839-848. doi:10.1148/radiol.2393050027

[38] S. M. Shapiro, "Bilirubin Toxicity in the Developing Nervous System," Pediatric Neurology, Vol. 29, No. 5, 2003, pp. 410-421. doi:10.1016/j.pediatrneurol.2003.09.011

[39] J. F. Watchko, "Kernicterus and the Molecular Mechanisms of Bilirubin-Induced CNS Injury in Newborns," Neuromolecular Medecine, Vol. 8, No. 4, 2006, pp. 513529. doi:10.1385/NMM:8:4:513

[40] D. Martino and G. Giovannoni, "Antibasal Ganglia Antibodies and Their Relevance to Movement Disorders". Current Opinion in Neurology, Vol. 17, No. 4, 2004, pp. 425-432. doi:10.1097/01.wco.0000137532.76491.19

[41] S. T. Shulman, "Pediatric Autoimmune Neuropsychiatric Disorders Associated with Streptococci (PANDAS): Update," Current Opinion in Pediatrics, Vol. 21, No. 1, 2009, pp. 127-130. doi:10.1097/MOP.0b013e32831db2c4

[42] R. C. Dale, A. J. Church, R. A. Surtees, A. J. Lees, J. E. Adcock, B. Harding, B. G. Neville and G. Giovannoni, "Encephalitis Lethargica Syndrome: 20 New Cases and Evidence of Basal Ganglia Autoimmunity," Brain, Vol. 127, No. Pt1, 2004, pp. 21-33. doi:10.1093/brain/awh008

[43] M. W. Kullnat and R. P. Morse, "Choreoathetosis after Herpes Simplex Encephalitis with Basal Ganglia Involvement on MRI," Pediatrics, Vol. 121, No. 4, 2008, pp. e1003-1007. doi:10.1542/peds.2007-0813

[44] S. Ashwal, B. S. Russman, P. A Blasco, G. Miller, A. Sandler, M. Shevell and R. Stevenson, Quality Standards Subcommittee of the American Academy of Neurology; Practice Committee of the Child Neurology Society, "Practice Parameter: Diagnostic Assessment of the child with cerebral Palsy: Report of the Quality Standards Subcommittee of the American Academy of Neurology and the Practice Committee of the Child Neurology Society," Neurology, Vol. 62, No. 6, 2004, pp. 851-863.

[45] A. H. Hoon Jr., E. M. Reinhardt, R. I. Kelley, S. N. Breiter, D. H. Morton, S. B. Naidu and M. V. Johnston, "Brain Magnetic Resonance Imaging in Suspected Extrapyramidal Cerebral Palsy: Observations in Distinguishing Genetic- Metabolic from Acquired Cause," Journal of Pediatrics, Vol. 131, No. 2, 1997, pp. 240-245. doi:10.1016/S0022-3476(97)70160-4

[46] M. V. Johnston and A. H. Hoon Jr., "Cerebral Palsy,"
Neuromolecular Medecine, Vol. 8, No. 4, 2006, pp. 435450. doi:10.1385/NMM:8:4:435

[47] B. S. Russman and S. Ashwal, "Evaluation of the Child with Cerebral Palsy," Seminar in Pediatric Neurology, Vol. 11, No. 1, 2004, pp. 47-57. doi:10.1016/j.spen.2004.01.007

[48] K. Gkoltsiou, M. Tzoufi, S. Counsell, M. Rutherford and F. Cowan, "Serial Brain MRI and Ultrasound Findings: Relation to Gestational Age, Bilirubin Level, Neonatal Neurologic Status and Neurodevelopmental Outcome in Infants at Risk of kernicterUs," Early Human Development, Vol. 84, No. 12, 2008, pp. 829-838. doi:10.1016/j.earlhumdev.2008.09.008

[49] D. L. Gilbert, "Drug-Induced Movement Disorders in Children," Annals of the New York Academy of Sciences, Vol. 1142, 2008, pp. 72-84. doi:10.1196/annals.1444.005

[50] E. Y. Uc and R. L. Rodnitzky, "Childhood Dystonia," Seminar in Pediatric Neurology, Vol. 10, No. 1, 2003, pp. 52-61. doi:10.1016/S1071-9091(02)00010-4

[51] C. U. Correll and E. M. Schenk, "Tardive Dyskinesia and New Antipsychotics," Current Opinion in Psychiatry, Vol. 21, No. 2, 2008, pp. 151-156. doi:10.1097/YCO.0b013e3282f53132

[52] C. U. Correll and J. M. Kane, "One-Year Incidence Rates of Tardive Dyskinesia in Children and Adolescents Treated with Second-Generation Antipsychotics: A Systematic Review," Journal of Child and Adolescent Psychopharmacology, Vol. 17, No. 5, 2007, pp. 647-656. doi:10.1089/cap.2006.0117

[53] N. Gordon, "Sydenham's Chorea and Its Complications Affecting the Nervous System," Brain and Development, Vol. 31, No. 1, 2009, pp. 11-14. doi:10.1016/j.braindev.2008.05.001

[54] R. Kurlan, D. Johnson, E. L. Kaplan and the Tourette Syndrome Study Group, "Streptococcal Infection and Exacerbations of Childhood Tics and Obsessive-Compulsive Symptoms: A Prospective Blinded Cohort Study," Pediatrics, Vol. 121, No. 6, 2008, pp. 1188-1197. doi:10.1542/peds.2007-2657

[55] S. E. Swedo, H. L. Leonard, M. Garvey, B. Mittleman, A. J. Allen, S. Perlmutter, L. Lougee, S. Dow, J. Zamkoff and B. K. Dubbert, "Pediatric Autoimmune Neuropsychiatric Disorders Associated with Streptococcal Infections: Clinical Description of the First 50 Cases," American Journal of Psychiatry, Vol. 155, No. 2, 1998, pp. 22642371.

[56] V. Gabbay, B. J. Coffey, J. S. Babb, L. Meyer, C. Wachtel, S. Anam and B. Rabinovitz, "Pediatric Autoimmune Neuropsychiatric Disorders Associated with Streptococcus: Comparison of Diagnosis and Treatment in the Community and at a Specialty Clinic," Pediatrics, Vol. 122, No. 3, 2008, pp. 273-278. doi:10.1542/peds.2007-1307

[57] S. J. Hayflick, S. K. Westaway, B. Levinson, B. Zhou, M. A. Johnson, K. H. Ching and J. Gitschier, "Genetic, Clinical, and Radiographic Delineation of HallervordenSpatz Syndrome," New England Journal of Medicine, Vol. 348, No. 1, 2003, pp. 33-40. doi:10.1056/NEJMoa020817

[58] A. Machado, H. F. Chien, M. M. Deguti, E, Cançado R. S. 
Azevedo, M. Scaff and E. R. Barbosa, "Neurological Manifestations in Wilson's Disease: Report of 119 Cases," Movement Disorder, Vol. 21, No. 2, 2006, pp. 2192-2196. doi: $10.1002 / \mathrm{mds} .21170$

[59] J. Klepper and B. Leiendecker, "GLUT1 Deficiency Syndrome: 2007 Update," Developmental Medicine and Child Neurology, Vol. 49, No. 9, 2007, pp. 707-716. doi:10.1111/j.1469-8749.2007.00707.x

[60] J. W. Mink and L. S. Dure, "Paroxysmal Movement Disorders in Childhood," In: B. L. Maria, Ed., Current Management in Child Neurology, 3rd Edition, BC Decker, Hamilton (Canada), 2005, p. 427.

[61] N. Kabakuş and A. Kurt, "Sandifer Syndrome: A continuing Problem of Misdiagnosis," Pediatric International, Vol. 48, No. 6, 2006, pp. 622-625. doi:10.1111/j.1442-200X.2006.02280.x

[62] A. S. Golden, S. R. Haut and S. L. Moshé, "Nonepileptic Uses of Antiepileptic Drugs in Children and Adolescents," Pediatric Neurology, Vol. 34, No. 6, 2006, pp. 421-432. doi:10.1016/j.pediatrneurol.2005.08.017

[63] F. J. Jiménez-Jiménez and P. J. García-Ruiz, "Pharmacological Options for the Treatment of Tourette's Disorder,” Drugs, Vol. 61, No. 15, 2001, pp. 2207-2220.

[64] M. A. Gerber, R. S. Baltimore, C. B. Eaton, M. Gewitz, A. H. Rowley, S. T. Shulman and K. A. Taubert, "Prevention of Rheumatic Fever and Diagnosis and Treatment of Acute Streptococcal Pharyngitis: A Scientific Statement from the American Heart Association Rheumatic Fever, Endocarditis, and Kawasaki Disease Committee of the Council on Cardiovascular Disease in the Young, the Interdisciplinary Council on Functional Genomics and Translational Biology, and the Interdisciplinary Council on Quality of Care and Outcomes Research: Endorsed by the American Academy of Pediatrics," Circulation, Vol. 119, No. 11, 2009, pp. 1541-1551. doi:10.1161/CIRCULATIONAHA.109.191959

[65] J. Rice and M. C. Waugh, "Pilot Study on Trihexyphenidyl in the Treatment of Dystonia in Children with Cerebral Palsy," Journal of Child Neurology, Vol. 24, No. 2, 2009, pp. 176-182. doi:10.1177/0883073808322668

[66] M. M. Qasaymeh and J. W. Mink, "New Treatments for Tic Disorders," Current Treatment Options in Neurology, Vol. 8, No. 6, 2006, pp. 465-473. doi:10.1007/s11940-006-0036-4

[67] R. Nicolson, B. Craven-Thuss, J. Smith, B. D. McKinlay and F. X. Castellanos, "A Randomized, Double-Blind, Placebo-Controlled Trial of Metoclopramide for the Treatment of Tourette's Disorder," Journal of the American Academy of Child and Adolescent Psychiatry, Vol. 44, No.
7, 2005, pp. 640-646. doi:10.1097/01.chi.0000163279.39598.44

[68] R. J. Stephens, C. Bassel and P. Sandor, "Olanzapine in the Treatment of Aggression and Tics in Children with Tourette's Syndrome: A Pilot Study," Journal of Child and Adolescent Psychopharmacology, Vol. 14, No. 2, 2004, pp. 255-266. doi:10.1089/1044546041648959

[69] G. R. Gaffney, P. J. Perry, B. C. Lund, K. A. Bever-Stille, S. Arndt and S. Kuperman, "Risperidone versus Clonidine in the Treatment of Children and Adolescents with Tourette's Syndrome," Journal of the American Academy of Child and Adolescent Psychiatry, Vol. 41, No. 3, 2002, pp. 330-336. doi:10.1097/00004583-200203000-00013

[70] Tourette's Syndrome Study Group, "Treatment of ADHD in Children with Tics: A Randomized Controlled Trial," Neurology, Vol. 58, No. 4, 2002, pp. 527-536.

[71] M. Vidailhet, L. Vercueil, J. L. Houeto, P. Krystkowiak, C. Lagrange, J. Yelnik, E. Bardinet, A. L. Benabid, S. Navarro, D. Dormont, S. Grand, S. Blond, C. Ardouin, B. Pillon, K. Dujardin, V. Hahn-Barma, Y. Agid, A. Destée, P. Pollak and French SPIDY Study Group, "Bilateral, Pallidal Deep Brainstimulation in Primary Generalized Dystonia: A Prospective 3 Year Follow-Up Study," Lancet Neurology, Vol. 6, No. 3, 2007, pp. 223-229.

[72] W. A. Marks, J. Honeycutt, F. Acosta and M. Reed, "Deep Brain Stimulation for Childhood onset Dystonias at Cook Children's Medical Center, a Community Based Pediatric Hospital," Semiar in Pediatric Neurology, Vol. 16, No. 2, 2009, pp. 90-98.

doi:10.1016/j.spen.2009.04.001

[73] D. Servello, M. Porta, M. Sassi, A. Brambilla and M. M. Robertson, "Deep Brain Stimulation in 18 Patients with Severe Gilles de la Tourette Syndrome Refractory to Treatment: The Surgery and Stimulation," Journal of Neurology Neurosurgery and Psychiatry, Vol. 79, No. 2, 2008, pp. 136-142. doi:10.1136/jnnp.2006.104067

[74] R. J. Maciunas, B. N. Maddux, D. E. Riley, C. M. Whitney, M. R. Schoenberg, P. J. Ogrocki, J. M. Albert and D. J. Gould, "Prospective Randomized Double-Blind Trial of Bilateral Thalamic Deep Brain Stimulation in Adults with Tourette Syndrome," Journal of Neurosurgery, Vol. 107, No. 5, 2007 pp. 1004-1014. doi:10.3171/JNS-07/11/1004

[75] J. Shahed, J. Poysky, C. Kenney, R. Simpson and J. Jankovic, "GPi Deep Brain Stimulation for Tourette Syndrome Improves Tics and Psychiatric Comorbidities," Neurology, Vol. 68, No. 2, 2007, pp 159-160. doi:10.1212/01.wnl.0000250354.81556.90 